\title{
Adsorption of Alizarin Red S Dye by Carbon Nanotubes: An Experimental and Theoretical Investigation
}

\author{
Fernando M. Machado, ${ }^{* \dagger}{ }^{\dagger}$ Sophia A. Carmalin, ${ }^{\ddagger}$ Eder C. Lima, ${ }^{\S}$ Silvio L. P. Dias, ${ }^{\S}$ Lizie D. T. Prola, ${ }^{\S}$
} Caroline Saucier, ${ }^{\S}$ Iuri M. Jauris," Ivana Zanella," and Solange B. Fagan"

${ }^{\dagger}$ Technology Development Center, Federal University of Pelotas (UFPEL), R. Gomes Carneiro 1, 96010-610, Pelotas, RS, Brazil

${ }^{\ddagger}$ National Environmental Engineering Research Institute (NEERI), Chennai Zonal Laboratory, CSIR Campus, Taramani, Chennai 600113, India

${ }^{\S}$ Institute of Chemistry, Federal University of Rio Grande do Sul (UFRGS), Av. Bento Gonçalves 9500, Postal Box 15003, 91501-970, Porto Alegre, RS, Brazil

"Área de Ciências Tecnológicas, Centro Universitário Franciscano (UNIFRA), R. dos Andradas 1614, 97010-032, Santa Maria, RS, Brazil

Supporting Information

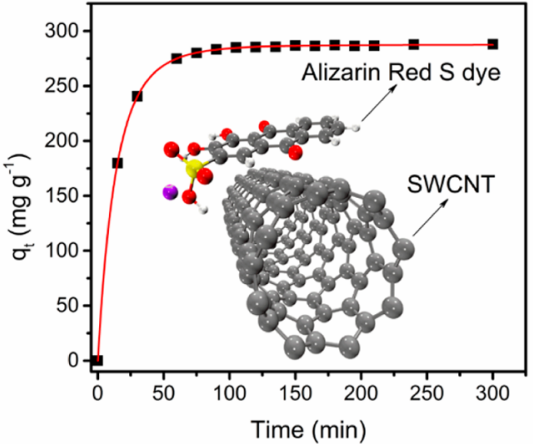

ABSTRACT: This study evaluated the feasibility of removing Alizarin Red S dye (ARS) from aqueous solutions, using nanoadsorbents such as single and multiwalled carbon nanotubes (SWCNT and MWCNT, respectively). The effect of $\mathrm{pH}$, shaking time, and temperature on adsorption was studied. The $\mathrm{pH} 2.0$ was observed to show optimum removal for both of the carbon nanotubes. The equilibrium time (298-318 K) was fixed at 65 and $100 \mathrm{~min}$ for SWCNT and MWCNT, respectively. The kinetics of adsorption was calculated using pseudo-first-order, pseudo-second-order, and general-order equations. The calculations revealed that the general-order kinetic equation best-fit the adsorption data. The Liu isotherm model best fit the equilibrium data $(298-318 \mathrm{~K})$. The maximum sorption capacity at $318 \mathrm{~K}$ for ARS dye was 312.5 and $135.2 \mathrm{mg} \mathrm{g}^{-1}$ for SWCNT and MWCNT, respectively. Change in entropy $\left(\Delta S^{\circ}\right)$, Gibb's free energy change $\left(\Delta G^{\circ}\right)$, and enthalpy $\left(\Delta H^{\circ}\right)$ were calculated for the adsorption of ARS dye. The electrostatic interaction between nanoadsorbent-adsorbate was conveyed using the magnitude of change in enthalpy. Ab initio simulation was used to study the interaction of ARS with $(5,5)$ and $(8,0)$ SWCNTs, and $(16,0)$ and $(25,0)$ SWCNTs with and without vacancy. The theoretical calculations showed that the binding energies between ARS dye and SWCNTs are enhanced as the nanotube diameter gets bigger; however, the distance of binding remains unchanged. Therefore, the results from first principle calculations indicated that electrostatic interaction may be responsible for the adsorption of ARS dye onto SWCNT. The theoretical outcomes were found to be in coordination with the experimental estimates.

\section{INTRODUCTION}

The Alizarin Red S is a durable, anionic dye that belongs to the anthraquinone group of dyes. It is generally used as a staining agent in textile industries. ${ }^{1}$ This dye is also used to stain biological specimens such as mineralized bones in vertebrate groups and small invertebrate embryos. ${ }^{2}$ This synthetic dye is a strong oxidizing agent, and hence must be stored away from heat and humidity. ${ }^{3}$ The ARS is a chemically stable and nonbiodegradable dye and hence cannot be completely mineralized by conventional treatment processes. ${ }^{4}$ It is resistant to degradation due to its structure that offers high thermal, optical, and physicochemical stability. ${ }^{5}$ Hence, remediation studies are focused on developing easy, simple, and efficient processes for their safe and economic removal.

Received: April 16, 2016

Revised: July 27, 2016

Published: August 3, 2016 
Improper discharge of synthetic dye-containing wastewater can cause unfavorable effects on aquatic life by obstructing light permeation and impeding photosynthesis in aquatic flora. ${ }^{6}$ In humans, synthetic dyes can cause allergies, skin itching or sores, allergic reaction in eyes, and irritation in the mucous membrane and the respiratory tract. ${ }^{7,8}$ In extreme cases, it can induce cell mutation and cancer. ${ }^{7,8}$ Hence, treatment of such wastewaters is an important environmental concern.

Adsorption is a simple, easy, efficient, and economical method for the removal of dyes. ${ }^{9-12}$ Here, the contaminants are relocated from an aqueous phase to the adsorbents surface. $^{13,14}$ After adsorption of the pollutant, the treated effluent can be safely let out or recycled. ${ }^{14,15}$ Some of the adsorbents can be restored and reprocessed after adsorption, thus making the process more economical and environmentally friendly. ${ }^{15,16}$

Removal of synthetic dye pigments using several adsorbents has been reported in the literature. ${ }^{9-16}$ Gold nanoparticles loaded activated carbon, ${ }^{4}$ polypyrrole-coated magnetic nanoparticles, ${ }^{5}$ mustard husk biomass, ${ }^{17}$ and activated carbon $/ \gamma$ $\mathrm{Fe}_{2} \mathrm{O}_{3}{ }^{18}$ have been recently used for the adsorption of ARS dye.

Multiwalled carbon nanotubes have been efficiently used for the adsorption of ARS dye from solution. ${ }^{3}$ Carbon nanotubes (CNT) have recently gained attraction due to their interesting textural properties, large surface area and suitable pore size, etc., ${ }^{16,19-21}$ for the adsorption of dyes from wastewater. Their structure favors the interaction with organic dye molecules through hydrophobic interfaces, electrostatic forces, van der Waals force, $\pi-\pi$ stacking, and hydrogen bonding. ${ }^{19-21}$ Despite the great potential offered by CNTs, there are few experimental and theoretical studies reporting the interaction of CNT, especially SWCNT, with synthetic dyes. ${ }^{21}$

In the present work, SWCNT and MWCNT were used in a novel way for the adsorption of ARS dye from the liquid phase. To comprehend the interaction mechanism of ARS dye on a CNT surface, ab initio calculations based on Density Functional Theory (DFT) evaluation of data ${ }^{21,22}$ were conducted. The studies also evaluated the changes in the adsorption process in line with the changes in SWCNT diameter. Electrostatic interaction was predicted from the calculations of binding energies. The theoretical outcomes were found to be in coordination with the experimental estimates.

\section{MATERIALS AND METHODS}

2.1. Materials, Chemical Reagents, and Solutions. SWCNT and MWCNT (95\% pure) were supplied by NanoAmor (Houston, TX) and Bayer (Germany), respectively. The supplied CNTs were prepared by chemical vapor deposition (CCVD) mode. ${ }^{21}$ Both CNTs were used without further purification. Surface characterization and porosity estimation of both CNTs were done using a Quantachrome NOVA1000e analyzer. Porosity, surface area BJH (Barret, Joyner, and Halenda), and multipoint BET (BrunauerEmmett-Teller) were analyzed. ${ }^{16,21}$ Fourier transform infrared (FTIR) spectroscopies of the CNTs were performed using a 640-IR Varian spectrometer (resolution $4 \mathrm{~cm}^{-1}$ ). ${ }^{16,21}$

The textile dye Alizarin Red S (sodium alizarin sulfonate, 95\% pure; C.I. 58005; CAS 130-22-3; $\mathrm{C}_{14} \mathrm{H}_{7} \mathrm{NaO}_{7} \mathrm{~S}$; $342.25 \mathrm{~g}$ $\mathrm{mol}^{-1}$; see Figure S1) was supplied by Dinâmica (Diadema, Brazil). The dye was used as such, with no further treatment.

ARS dye stock solution $\left(5.00 \mathrm{~g} \mathrm{~L}^{-1}\right)$ was made by mixing an appropriately weighed quantity of dye in a fixed volume of deionized water. The stock solution was appropriately diluted to prepare working dye solutions of required strengths. $\mathrm{pH}$ values of the adsorbates were adjusted by employing $0.10 \mathrm{~mol}$ $\mathrm{L}^{-1} \mathrm{HCl} / \mathrm{NaOH}$ solution. A Schott Lab $\mathrm{pH}$ meter was used to record the $\mathrm{pH}$ of the solutions.

2.2. Adsorption Studies. Adsorption experiments using SWCNT and MWCNT adsorbents were carried out to assess the elimination of ARS dye from liquid media. The adsorption experiments were performed in triplicate by means of batch process. $30.0 \mathrm{mg}$ of CNT was taken in a $50.0 \mathrm{~mL}$ Falcon tube holding $20.0 \mathrm{~mL}$ of ARS dye solutions whose concentrations ranged from 100.0 to $1000.0 \mathrm{mg} \mathrm{L}^{-1}$. The Falcon tube was shaken for a fixed time interval (15-300 $\mathrm{min}$ at temperatures ranging from 298 to $318 \mathrm{~K}$ ). The agitation time fixed for SWCNT and MWCNT during kinetic experiments was 65 and $100 \mathrm{~min}$, respectively. The $\mathrm{pH}$ of the adsorbate ranged from 2.0 to 10.0. To separate the adsorbent from the solution, the falcon tubes were centrifuged at $14000 \mathrm{rpm}$ for $5 \mathrm{~min}$ using a UniCen $M$ centrifuge. Subsequently, $1-10 \mathrm{~mL}$ aliquots of the supernatant were analyzed using a T90 Double Beam UV visible spectrophotometer. Absorbance was recorded at $\lambda_{\max }$ $421 \mathrm{~nm}$ for ARS dye. The percentage removal efficiency of the dye from aqueous solutions using CNTs was assessed applying eqs 1 and 2 .

$$
q=\frac{\left(C_{\mathrm{o}}-C_{\mathrm{f}}\right)}{m} \cdot V
$$

and

$$
\text { percentage removal }=100 \cdot \frac{\left(C_{o}-C_{f}\right)}{C_{o}}
$$

where $q$ is the quantity of ARS dye taken up by CNTs, $\mathrm{mg} \mathrm{g}^{-1}$; $C_{\mathrm{o}}$ is the initial strength of the ARS dye $\left(\mathrm{mg} \mathrm{L}^{-1}\right) ; C_{\mathrm{f}}$ is the dye strength after adsorption, $\mathrm{mg} \mathrm{L}^{-1} ; V$ is the volume of the ARS dye, $L$; and $m$ is the mass of the adsorbent, $g$.

Two simulated effluents were formulated using various quantities of different dyes, to assess the adsorption efficiency of SWCNT and MWCNT. pH values of these effluents were initially adjusted to 2.0 and later were shaken with $30.0 \mathrm{mg}$ of CNTs. The results demonstrated good removal $(>95 \%) .{ }^{6}$ The compositions of the effluents are shown in Table 1.

2.3. Theoretical Calculations. The structural and electronic properties of ARS dye interacting with $(5,5)$ and

Table 1. Formulation of the Synthetic Dye Effluents

\begin{tabular}{lccc} 
& & \multicolumn{2}{c}{ concentration, $\mathrm{mg} \mathrm{L}^{-1}$} \\
\cline { 3 - 4 } & $\lambda_{\max }, \mathrm{nm}$ & effluent A & effluent B \\
Anionic Dyes & & & \\
Alizarin Red S & 421 & 20.00 & 40.00 \\
Congo Red & 500 & 5.00 & 10.00 \\
Procion Blue MX-R & 594 & 5.00 & 10.00 \\
Cibacron Brilliant Yellow 3G-P & 402 & 5.00 & 10.00 \\
Reactive Orange 16 & 493 & 5.00 & 10.00 \\
Inorganics & & & \\
sodium chloride & & 150.00 & 300.00 \\
sodium carbonate & & 100.00 & 200.00 \\
sodium acetate & & 100.00 & 200.00 \\
acetic acid & & 100.00 & 200.00 \\
humic acid & & 25.00 & 50.00 \\
sodium dodecyl sulfate & & 25.00 & 50.00 \\
pH & & 2.0 & 2.0
\end{tabular}


$(8,0)$ SWCNTs with and without vacancy were simulated, in different configurations. Ab initio calculations based on DFT ${ }^{23}$ was used via SIESTA code. ${ }^{24}$ Furthermore, the configurations for the ARS dye with pristine $(8,0)$ SWCNT and ARS dye with pristine $(16,0)$ and $(25,0)$ SWCNTs were compared. Code SIESTA applies a linear combination of atomic orbitals (LCAO) with atomic numeric sets, ${ }^{25}$ to solve self-consistent Kohn-Sham equations. The local density approximation (LDA) was adapted to obtain the correlation coefficient. The parametrization scheme of Perdew-Zunger was hence proved. $^{26,27}$ The electrons in the core were designated pseudopotentials by modified Troullier-Martins method. ${ }^{28} \mathrm{~A}$ double- $\zeta$ plus polarization (DZP) ${ }^{24}$ was applied to magnify the pseudowave function analysis. A series of pseudoatomic orbitals was controlled by energy shifts to about $0.05 \mathrm{eV}$. A $200 \mathrm{Ry}$ charge density cutoff was assumed for grid incorporation. Twelve Monkhorst-Pack $k$-points were used $^{29}$ alongside the CNTs axis for the integration over the first Brillouin zone. Feynman-Hellmann forces were applied to obtain minimization of energy. Pulay corrections were incorporated to accomplish improved atomic structures. The atomic positions were fixed by means of the conjugate gradient (CG) algorithm until the remaining strength applied on each atom was $<0.05$ $\mathrm{eV} / \AA^{24}{ }^{24}$ Periodic boundary conditions (1D) and the supercell approach along the CNTs axis were used. A supercell length of $14.76 \AA$ equivalent to 6 unit cells were used for pristine $(5,5)$ SWCNT and $(5,5)$ SWCNT with a vacancy, interacting with the ARS molecule. For $(8,0)$ SWCNTs, with and without vacancy, $(16,0)$ and $(25,0)$ SWCNTs interacted with the ARS. This employed 4 unit cells equivalent to $17.00 \AA$, the supercell length. The images did not interlap with each other, because their closest distance was approximately 2-3 times the length of the supercell. The binding energy $\left(E_{\mathrm{b}}\right)$ among SWCNT and the ARS molecule was deliberated applying the basis set superposition error (BSSE). ${ }^{30}$

The SIESTA code practices on wave functions; hence, this correction is essential. This application originates error while calculating the $E_{\mathrm{b}}$ of a system that comprises energy changes of a system. Equation 3 may rectify this error:

$$
\begin{aligned}
E_{\mathrm{b}} & =-\left[E(\mathrm{SWCNT}+\mathrm{ARS})-E\left(\mathrm{SWCNT}+\mathrm{ARS}_{\text {ghost }}\right)\right. \\
& \left.-E\left(\mathrm{SWCNT}_{\text {ghost }}+\mathrm{ARS}\right)\right]
\end{aligned}
$$

where $E(S W C N T+A R S)$ is the total energy of SWCNT plus ARS dye molecule. The subscript "ghost" is the additional basis wave functions focused at ARS or SWCNT, but without any atomic potential. The values for the minimum distances $\left(d_{\mathrm{b}}\right)$ between the SWCNT and ARS dye molecules were obtained from a plane tangent to the nanotube to the nearest atom of the ARS dye molecules.

\section{RESULTS AND DISCUSSION}

3.1. Effect of pH on Adsorption of ARS Dye. Sorption capacity is greatly influenced by the $\mathrm{pH}$ of adsorbate solution. $^{31,32}$ Different adsorbents possess different optimum $\mathrm{pH}$ values for adsorption of different adsorbates. ${ }^{31,32}$ In this study, the initial $\mathrm{pH}$ of adsorbate was varied from 2.0 to $\mathrm{pH}$ 10.0 (Figure 1). It was observed at $\mathrm{pH} 2.0$ that the adsorption capacity of ARS onto SWCNT and MWCNT was maximum. An early adsorption was observed on the carbon nanotubes. $^{16,19,21}$

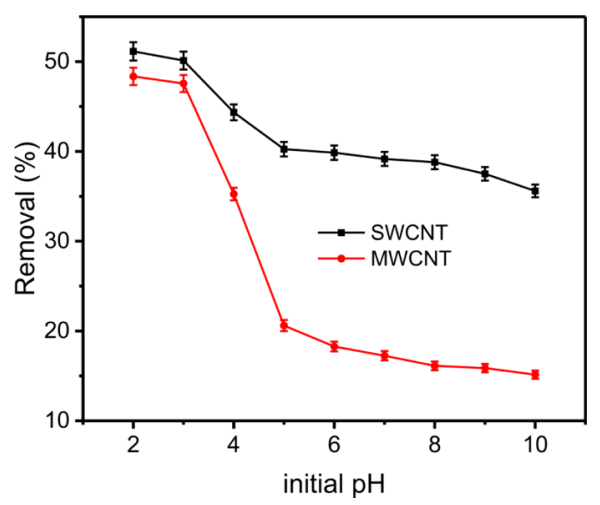

Figure 1. Adsorption of ARS dye and influence of $\mathrm{pH}$ (adsorbents, SWCNT and MWCNT; initial dye concentraion, $600 \mathrm{mg} \mathrm{L}^{-1}$ ).

Observing Figure S1, the phenolic functional groups present in the dye get protonated, while the sulfonic group was not protonated at $\mathrm{pH}$ 2.0. This may be due to the fact that these groups are strongly acidic, presenting negative $\mathrm{p} K_{\mathrm{a}}$ values, as reported earlier. ${ }^{15,16}$ It may be inferred from these results that the anionic dye was adsorbed in the positively charged carbon nanotube at $\mathrm{pH} 2$, by electrostatic attraction. It has been reported in the literature ${ }^{21}$ that the $\mathrm{pH}_{\mathrm{pzc}}$ values of SWCNT and MWCNT are 6.73 and 6.85, respectively. Therefore, these nanoadsorbents at $\mathrm{pH} 2.0$ (value lower than the $\mathrm{pH}_{\mathrm{pzc}}$ ) are positively charged. The mechanism of adsorption should be an electrostatic interaction between the positively charged CNT and negatively charged ARS. It was also observed that as the $\mathrm{pH}$ was raised from 2.0 to 10.0, the \% removal of ARS by SWCNT was decreased by $15.54 \%$. However, while using MWCNT, the $\%$ removal reduced by $33.21 \%$ for the same $\mathrm{pH}$ interval. This lower difference for SWCNT should be attributed to other interactions of the adsorbent with the adsorbate besides the electrostatic attraction described above. For all other experiments, the initial $\mathrm{pH}$ of adsorbate solution was kept at 2.0 for both of the nanoadsorbents.

3.2. Adsorption Kinetics. The kinetics of ARS dye adsorption onto carbon nanotubes was explored using pseudo-second-order, nonlinear pseudo-first-order, and general-order kinetic models. The fitting parameters from the models are shown in Figure 2 and Table 2. The level to which each model fits was shown using standard deviation (SD) values of residues. The lower were the the $\mathrm{SD}$ values, the greater was the precision between theoretical and experimental $q$ values. To demonstrate how much each model fits, the SD ratio was calculated. The $\mathrm{SD}$ ratio from the general-order kinetic model was 1.00, while for the pseudo-first-order model the same ranges from 4.32 to 5.27 . For the pseudo-secondorder model, the same ranges from 8.2 to 14.4. From the above data, it may be seen that the general-order kinetic model describes the best sorption kinetics.

It is not appropriate to compare the rates of the kinetics of adsorption of the different carbon nanotubes because the units of the kinetic rate constants are different. The time required to attain $50 \%$ of adsorption capacity at equilibrium $\left(q_{\mathrm{e}}\right)$ is half-life $\left(t_{1 / 2}\right)$. It was calculated by interpolation from the kinetic model fitting curve. It was observed that $t_{1 / 2}$ is $<17 \mathrm{~min}$ for all of the carbon nanotubes using initial ARS concentrations of $800.0 \mathrm{mg}$ $\mathrm{L}^{-1}$.

In the general-order kinetic model plot for ARS dye adsorption, an interpolation was made to estimate the time 

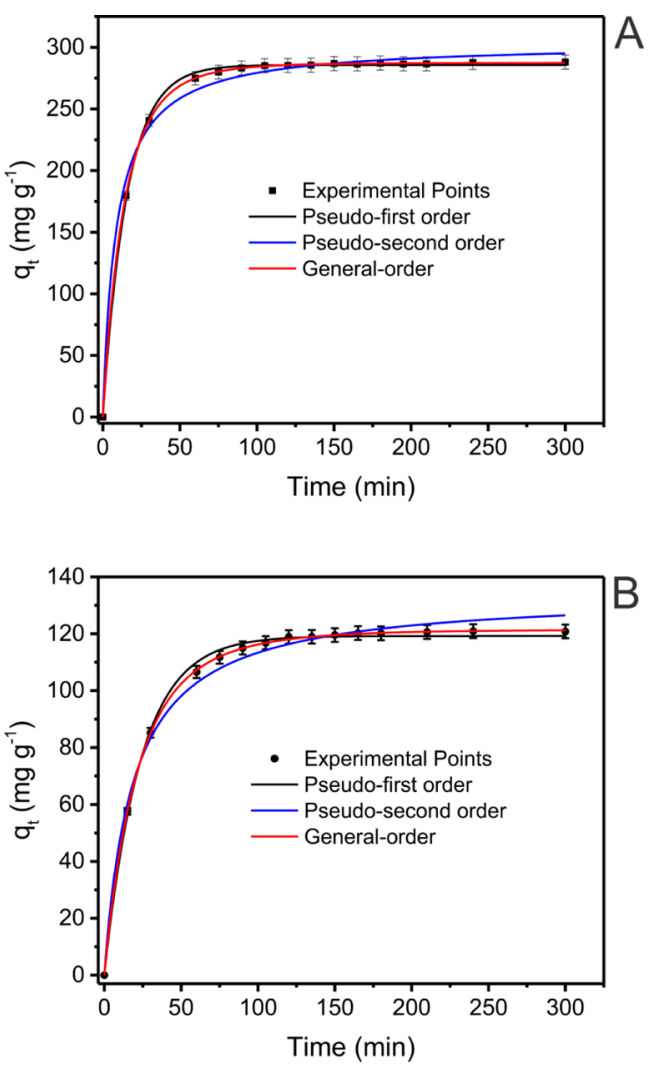

Figure 2. Kinetic curves for ARS adsorption on (A) SWCNT and (B) MWCNT. Conditions: $\mathrm{pH}, 2.0$; adsorbent mass, $30.0 \mathrm{mg}$; conc, 800.0 $\mathrm{mg} \mathrm{L}^{-1}$; temperature, $298 \mathrm{~K}$.

\section{Table 2. Kinetics of ARS Dye Adsorption ${ }^{a}$}

\begin{tabular}{lcc} 
& SWCNT & MWCNT \\
Pseudo-First-Order & & \\
$k_{1}\left(\mathrm{~min}^{-1}\right)$ & 0.06381 & 0.04103 \\
$q_{\mathrm{e}}\left(\mathrm{mg} \mathrm{g}^{-1}\right)$ & 285.7 & 119.6 \\
$t_{1 / 2}\left(\mathrm{~min}^{2}\right)$ & 10.86 & 16.90 \\
$R_{\mathrm{adj}}^{2}$ & 0.9991 & 0.9980 \\
$\mathrm{SD}\left(\mathrm{mg} \mathrm{g}^{-1}\right)$ & 2.275 & 1.517 \\
Pseudo-Second-Order & & \\
$k_{2}\left(\mathrm{~g} \mathrm{mg}^{-1} \mathrm{~min}^{-1}\right)$ & $3.774 \times 10^{-4}$ & $4.571 \times 10^{-4}$ \\
$q_{\mathrm{e}}\left(\mathrm{mg} \mathrm{g}^{-1}\right)$ & 303.7 & 132.4 \\
$t_{1 / 2}\left(\mathrm{~min}^{2}\right)$ & 8.726 & 16.52 \\
$R_{\mathrm{adj}}{ }^{2}$ & 0.9930 & 0.9927 \\
$\mathrm{SD}\left(\mathrm{mg} \mathrm{g}^{-1}\right)$ & 6.191 & 2.869 \\
$\mathrm{General}^{-O r d e r}$ & & \\
$k_{\mathrm{N}}\left[\mathrm{min}^{-1}\left(\mathrm{~g} \mathrm{mg}^{-1}\right)^{n-1}\right]$ & 0.02408 & 0.01540 \\
$q_{\mathrm{e}}\left(\mathrm{mg} \mathrm{g}^{-1}\right)$ & 287.4 & 121.5 \\
$N$ & 1.194 & 1.229 \\
$t_{1 / 2}\left(\mathrm{~min}^{2}\right.$ & 10.27 & 16.28 \\
$t_{0.95}\left(\mathrm{~min}^{2}\right)$ & 56.25 & 93.26 \\
$R_{\mathrm{adj}}{ }^{2}$ & 0.9999 & 0.9999 \\
$\mathrm{SD}\left(\mathrm{mg} \mathrm{g}^{-1}\right)$ & 0.4313 & 0.3511 \\
\hline
\end{tabular}

${ }^{a}$ Conditions: adsorbents, SWCNT and MWCNT; mass of adsorbent, $30.0 \mathrm{mg}, \mathrm{pH}, 2.0$; initial ARS concentration, $800.0 \mathrm{mg} \mathrm{L}^{1}$; temperature, $298 \mathrm{~K}$.

required to reach equilibrium. The value of $q_{t}$ was $95 \%$. It was the maximum value of the theoretical $q_{\mathrm{e}}$ used. This time was defined as $t_{0.95}$. The $t_{0.95}$ was calculated only for the generalorder kinetic model, because it was the best fitting kinetic model in this work. Observing the values reported in Table 2, $t_{0.95}$ is 56.25 and $93.26 \mathrm{~min}$, for SWCNT and MWCNT, respectively. Taking into account the usage of higher concentrations of the dye, the equilibrium time could be higher as was already observed for other organic adsorbates. ${ }^{33}$ The contact time was fixed at 65 and $100 \mathrm{~min}$, for adsorption of ARS dye onto SWCNT and MWCNT, respectively, in the subsequent experiments.

3.3. Equilibrium Studies. Isothermal data were analyzed using Liu, Freundlich, and Langmuir isotherm models. The experiments were executed between 298 and $318 \mathrm{~K}$ under the following conditions: contact time was kept at 65 and $100 \mathrm{~min}$ for SWCNT and MWCNT, respectively, initial $\mathrm{pH}$ of ARS solutions was 2.0 , and adsorbent dosage was $1.5 \mathrm{~g} \mathrm{~L}^{-1}$. Figure 3
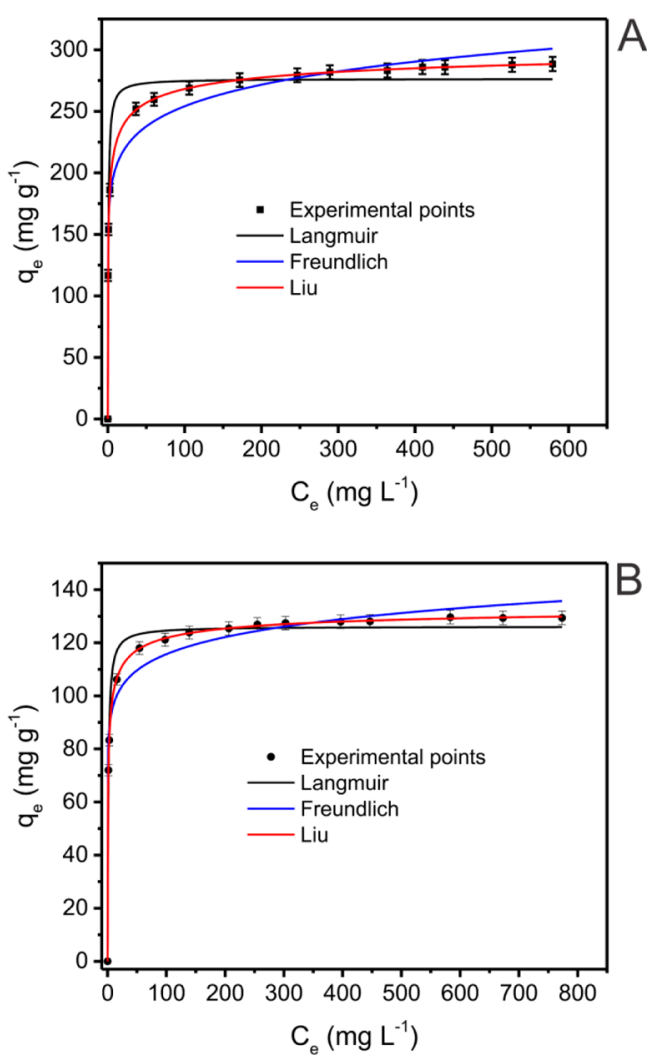

Figure 3. Adsorption isotherm plots of ARS onto (A) SWCNT and (B) MWCNT. Conditions: $\mathrm{pH}, 2.0$; adsorbent dosage, $1.5 \mathrm{~g} \mathrm{~L}^{-1}$; contact time, 65.0 and $100 \mathrm{~min}$ for SWCNT and MWCNT, respectively; temperature, $318 \mathrm{~K}$.

presents the adsorption isotherms of ARS dye onto (A) SWCNT and (B) MWCNT at $318 \mathrm{~K}$. Taking into account the $R_{\mathrm{adj}}^{2}$ and SD values, it can be determined that the Liu model best describes the equilibrium data of adsorption at all experimental temperatures (Table 3 ).

The Langmuir SD ratio ranged from 2.6 to 63.7 (SWCNT) and from 11.1 to 22.9 (MWCNT). The SD ratios for the Freundlich model range from 2.7 to 43.5 (SWCNT), and from 7.5 to 17.8 (MWCNT). SD ratio values for the Liu isotherm model were 1.0. This signifies that the theoretical sorption capacity was best projected by the Liu model $\left(q_{i, \text { model }}\right)$. The same was the closest to the experimental sorption capacity $\left(q_{i, \text { experimental }}\right)$. The $R_{\mathrm{adj}}^{2}$ values were found to be in agreement with the SD values, which confirms, among the other isotherm models, that the Liu isotherm was the best fitting model. 
Table 3. Langmuir, Freundlich, and Liu Isotherm Parameters for the Adsorption of ARS Dye onto SWCNT and MWCNT ${ }^{a}$

\begin{tabular}{|c|c|c|c|c|c|c|c|c|c|c|}
\hline & \multicolumn{5}{|c|}{ SWCNT } & \multicolumn{5}{|c|}{ MWCNT } \\
\hline & $298 \mathrm{~K}$ & $303 \mathrm{~K}$ & $308 \mathrm{~K}$ & $313 \mathrm{~K}$ & $318 \mathrm{~K}$ & $298 \mathrm{~K}$ & $303 \mathrm{~K}$ & $308 \mathrm{~K}$ & $313 \mathrm{~K}$ & $318 \mathrm{~K}$ \\
\hline \multicolumn{11}{|l|}{ Langmuir } \\
\hline$Q_{\max }\left(\mathrm{mg} \mathrm{g}^{-1}\right)$ & 281.6 & 287.5 & 275.8 & 273.9 & 276.4 & 118.6 & 119.2 & 112.2 & 119.1 & 126.1 \\
\hline$K_{\mathrm{L}}\left(\mathrm{L} \mathrm{mg}^{-1}\right)$ & 2.033 & 1.747 & 1.966 & 1.879 & 1.555 & 1.025 & 0.4963 & 16.56 & 0.8945 & 0.8074 \\
\hline$R_{\mathrm{adj}}^{2}$ & 0.9785 & 0.9566 & 0.9417 & 0.9528 & 0.9561 & 0.9735 & 0.9400 & 0.9345 & 0.9762 & 0.9844 \\
\hline $\mathrm{SD}\left(\mathrm{mg} \mathrm{g}^{-1}\right)$ & 12.24 & 18.60 & 20.44 & 17.98 & 17.63 & 5.208 & 8.932 & 9.061 & 5.026 & 4.391 \\
\hline \multicolumn{11}{|l|}{ Freudlich } \\
\hline$K_{\mathrm{F}}\left(\mathrm{mg} \mathrm{g}^{-1}\left(\mathrm{mg} \mathrm{L}^{-1}\right)^{-1 / n_{\mathrm{F}}}\right)$ & 175.8 & 174.3 & 166.2 & 165.5 & 163.1 & 83.30 & 71.57 & 67.60 & 78.17 & 80.76 \\
\hline$n_{\mathrm{F}}$ & 11.45 & 10.83 & 10.66 & 10.78 & 10.39 & 15.93 & 11.26 & 10.98 & 13.73 & 12.81 \\
\hline$R_{\mathrm{adj}}^{2}$ & 0.9769 & 0.9543 & 0.9728 & 0.9780 & 0.9764 & 0.9883 & 0.9555 & 0.9697 & 0.9890 & 0.9763 \\
\hline $\mathrm{SD}\left(\mathrm{mg} \mathrm{g}^{-1}\right)$ & 12.686 & 19.08 & 13.96 & 12.28 & 12.92 & 3.456 & 7.692 & 6.158 & 3.413 & 5.411 \\
\hline \multicolumn{11}{|l|}{ Liu } \\
\hline$Q_{\max }\left(\mathrm{mg} \mathrm{g}^{-1}\right)$ & 308.6 & 310.0 & 310.9 & 311.7 & 312.5 & 131.3 & 132.7 & 132.4 & 133.9 & 135.2 \\
\hline$K_{\mathrm{g}}\left(\mathrm{L} \mathrm{mg}^{-1}\right)$ & 1.824 & 1.569 & 1.358 & 1.178 & 1.033 & 1.809 & 1.550 & 1.2931 & 1.162 & 0.9724 \\
\hline$n_{\mathrm{L}}$ & 0.4084 & 0.4691 & 0.3816 & 0.3735 & 0.3879 & 0.3752 & 0.3521 & 0.3155 & 0.3609 & 0.4821 \\
\hline$R_{\mathrm{adj}}^{2}$ & 0.9968 & 0.9999 & 0.9999 & 0.9999 & 0.9999 & 0.9999 & 0.9999 & 0.9999 & 0.9998 & 0.9999 \\
\hline $\mathrm{SD}\left(\mathrm{mg} \mathrm{g}^{-1}\right)$ & 4.746 & 0.5043 & 0.3208 & 0.3150 & 0.4750 & 0.3856 & 0.4325 & 0.3959 & 0.4526 & 0.3830 \\
\hline
\end{tabular}

It was observed that the sorption capacity of SWCNT was about 2.3-fold higher than that of MWCNT for adsorption of ARS dye. The adsorption kinetics of ARS dye onto SWCNT was about $65.80 \%$ faster than MWCNT. The textural characteristics of CNTs explain these differences. ${ }^{21}$ The textural properties of the adsorbents analyzed from nitrogen adsorption-desorption curves show a specific surface area of 415.3 and $180.9 \mathrm{~m}^{2} \mathrm{~g}^{-1}$; total pore volume of 0.786 and 0.345 $\mathrm{cm}^{3} \mathrm{~g}^{-1}$; and average pore radius (BJH) of 1.52 and $3.81 \mathrm{~nm}$ for SWCNT and MWCNT, respectively. SWCNT presents a larger adsorption capacity and a faster kinetics when compared to MWCNT for the adsorption of ARS dye because the total pore volume and specific surface area of SWCNT are $127.8 \%$ and $129.5 \%$ higher than those for the MWCNT, respectively. Faster kinetics and higher sorption capacity associated with adsorption of different adsorbates have already been discussed in the literature. ${ }^{20,21}$ Furthermore, higher sorption capacity of SWCNT could be due to the occurrence of a larger amount of adsorption sites in SWCNT as compared to MWCNT. ${ }^{21,34}$

The higher pore size of MWCNT may be ascribed to the accumulated pores formed during CNT agglomeration. ${ }^{35} \mathrm{On}$ the other hand, SWCNTs stick to each other and form bundles with tens or hundreds of tubes due to van der Waals interactions. The textural properties are affected by the count of tubes in a bundle, because adsorption sites in a bundle are different from those in an individual nanotube. These adsorption sites are extremely interesting for adsorption of adsorbates as small as, for example, dyes. ${ }^{20}$ In contrast, MWCNTs do not occur in bundles. Their adsorption centers are comprised of aggregated pores with ends opening toward the external walls. ${ }^{20}$ The aggregated pores particularly play an important part in the adsorption of biotic pollutants, for example, viruses and bacteria. ${ }^{20}$

Table 4 presents a comparative-assessment of sorption capacities of ARS by different adsorbents. ${ }^{3-5,18,36-40}$ As shown in the table, both SWCNT and MWCNT nanoadsorbents presented good sorption capacities when compared to other adsorbents. SWCNT presented a higher sorption capacity among the 11 adsorbents considered, ${ }^{3-5,18,36-40}$ and MWCNT was found to be more effective than 10 other adsorbents of similar type. ${ }^{3-5,18,36-40}$ These results support the
Table 4. Comparisons of Adsorption Capacities of ARS Dye Using Different Adsorbents ${ }^{a}$

\begin{tabular}{lcl}
\multicolumn{1}{c}{ adsorbent } & $\mathrm{Q}_{\max }\left(\mathrm{mg} \mathrm{g}^{-1}\right)$ & ref \\
MWCNT & 161.29 & 3 \\
gold nanoparticles loaded on activated carbon & 123.45 & 4 \\
polypyrrole-coated magnetic nanoparticles & 116.3 & 5 \\
activated carbon $/ \gamma$ - $\mathrm{Fe}_{2} \mathrm{O}_{3}$ & 108.69 & 18 \\
activated carbon & 20 & 36 \\
Citrullus lanatus peels & 79.6 & 37 \\
magnetic chitosan & 40.1 & 38 \\
iron oxide-modified activated clay & 32.70 & 39 \\
olive stone & 16.01 & 40 \\
SWCNT & 312.5 & this work \\
MWCNT & 135.2 & this work
\end{tabular}

${ }^{a}$ Conditions: optimized experimental conditions in each study.

application of both CNTs as potential nanoadsorbents for real textile industry effluent treatment.

3.4. Adsorption Mechanism and Thermodynamics. Gibb's free energy $\left(\Delta \mathrm{G}^{\circ}\right)$, change in entropy $\left(\Delta S^{\circ}\right)$, and change in enthalpy $\left(\Delta H^{\circ}\right)$ are the thermodynamic parameters related to adsorption. They are calculated from the subsequent equations:

$$
\begin{aligned}
& \Delta G^{\circ}=\Delta H^{\circ}-T \Delta S^{\circ} \\
& \Delta G^{\circ}=-R T \ln (K)
\end{aligned}
$$

Equations 4 and 5 combine to give

$$
\ln (K)=\frac{\Delta S^{\circ}}{R}-\frac{\Delta H^{\circ}}{R} \times \frac{1}{T}
$$

where $T$ is the absolute temperature (kelvin), $R$ is the universal gas constant $\left(8.314 \mathrm{~J} \mathrm{~K}^{-1} \mathrm{~mol}^{-1}\right)$, and $K$ is the equilibrium adsorption constant of the best fit isotherm. It should be converted in $\mathrm{L} \mathrm{mol}^{-1}$ to be used in the eq 6 , as recommended earlier. $^{20}$

Assessment of the intercept and slope from the $\ln (K)$ versus $1 / T$ plot gives $\Delta S^{\circ}$ and $\Delta H^{\circ}$ values ${ }^{9,11-16,19,31}$ (see Table 5). The $R_{\mathrm{adj}}^{2}$ value was approximately 0.99 . This is a measure of the reliability of the $\Delta H^{\circ}$ and $\Delta S^{\circ}$ values. Table 5 presents the thermodynamic parameters. 
Table 5. Thermodynamic Parameters for ARS Dye Adsorption ${ }^{a}$

\begin{tabular}{|c|c|c|c|c|c|}
\hline & \multicolumn{5}{|c|}{ temperature $(\mathrm{K})$} \\
\hline & 298 & 303 & 308 & 313 & 318 \\
\hline \multicolumn{6}{|l|}{ SWCNT } \\
\hline$K_{\mathrm{g}}\left(\mathrm{L} \mathrm{mol}^{-1}\right)$ & $6.244 \times 10^{5}$ & $5.371 \times 10^{5}$ & $4.646 \times 10^{5}$ & $4.031 \times 10^{5}$ & $3.536 \times 10^{5}$ \\
\hline$\Delta G^{\circ}\left(\mathrm{kJ} \mathrm{mol}{ }^{-1}\right)$ & -33.06 & -33.24 & -33.41 & -33.59 & -33.78 \\
\hline$\Delta H^{\circ}\left(\mathrm{kJ} \mathrm{mol}{ }^{-1}\right)$ & -22.45 & & & & \\
\hline$\Delta S^{\circ}\left(\mathrm{J} \mathrm{K}^{-1} \mathrm{~mol}^{-1}\right)$ & 33.59 & & & & \\
\hline$R_{\mathrm{adj}}^{2}$ & 0.9999 & & & & \\
\hline \multicolumn{6}{|l|}{ MWCNT } \\
\hline$K_{\mathrm{g}}\left(\mathrm{L} \mathrm{mol}^{-1}\right)$ & $6.190 \times 10^{5}$ & $5.305 \times 10^{5}$ & $4.426 \times 10^{5}$ & $3.978 \times 10^{5}$ & $3.328 \times 10^{5}$ \\
\hline$\Delta G^{\circ}\left(\mathrm{kJ} \mathrm{mol}{ }^{-1}\right)$ & -33.04 & -33.21 & -33.29 & -33.55 & -33.62 \\
\hline$\Delta H^{\circ}\left(\mathrm{kJ} \mathrm{mol}{ }^{-1}\right)$ & -24.09 & & & & \\
\hline$\Delta S^{\circ}\left(\mathrm{J} \mathrm{K}^{-1} \mathrm{~mol}^{-1}\right)$ & 30.03 & & & & \\
\hline$R_{\mathrm{adj}}^{2}$ & 0.9939 & & & & \\
\hline
\end{tabular}

${ }^{a}$ Adsorbents: SWCNT and MWCNT. Adsorbent dosage $1.50 \mathrm{~g} \mathrm{~L}^{-1}, \mathrm{pH} 2.0$, contact time 65 min for SWCNT and 100 min for MWCNT, respectively.

The interactions between the adsorbent and the adsorbate may be classified into three, using the enthalpy values. They are (i) physical adsorption $\left(\Delta H^{\circ}<20 \mathrm{~kJ} \mathrm{~mol}^{-1}\right)$, (ii) electrostatic interaction $\left(20 \leq \Delta H^{\circ} \leq 80 \mathrm{~kJ} \mathrm{~mol}^{-1}\right.$ ), and (iii) chemical adsorption $\left(80<\Delta H^{\circ} \leq 450 \mathrm{~kJ} \mathrm{~mol}^{-1}\right)$. $^{21,41}$ The enthalpy values for the sorption of ARS dye onto the two carbon nanotubes match the electrostatic interaction (see Table 5). $\Delta H^{\circ}$ has negatives values, which signify that the interactions of the two carbon nanotubes with ARS dye are exothermic. ${ }^{41}$ The adsorption of ARS dye onto two CNT was spontaneous and favorable because $\Delta G^{\circ}$ values are negative. An upsurge in arbitrariness in the liquid/solid boundary was observed because $\Delta S^{\circ}$ has positive values. ARS dye was displaced from the aqueous phase when it was adsorbed onto the solid phase. Hence, the entropy of the system was enhanced. ${ }^{42,43}$

Adsorption mechanism has been proposed in Figure 4. First, the CNTs are submerged in a solution with $\mathrm{pH}<2.0$, due to which the functional groups $(\mathrm{OH}$ and carboxylates; see infrared spectra of nanoadsorbents in Figure S2) present in the nanotubes get protonated. Second, the separation of the agglomerates of ARS dye molecule in solution occurs. In this solution the ARS molecules are in an organized state, besides being hydrated. ${ }^{44}$ Before the dyes are adsorbed onto the adsorbent, the self-associated dye molecules should be separated. ${ }^{44}$ The dyes should then be dehydrated. In the case of ARS dye, this step was rapid. Third, there was development of an electrostatic attraction between the negatively charged ARS dyes and positively charged CNTs (at pH 2.0). This step may be the rate-controlling step. The $\Delta H^{\circ}\left(-22.45 \mathrm{~kJ} \mathrm{~mol}^{-1}\right)$ was consistent with the electrostatic attraction of CNTs.

3.5. Simulated Synthetic Effluent. The adsorption capacities of SWCNT and MWCNT were evaluated using two synthetic industrial effluents to find out if the adsorbents were suitable for industrial dye wastewater remediation (see Table 1). The two synthetic effluents were scanned in a UVvis spectrophotometer $(200-800 \mathrm{~nm})$, before and after adsorption (Figure 5). The \% removal of the dyes from the synthetic effluents was calculated using the area under the absorption bands.

The SWCNT adsorbed 97.50\% (effluent A) and 96.64\% (effluent B), and MWCNT adsorbed $96.10 \%$ (effluent A) and 95.93\% (effluent B). On the basis of these results, it was possible to infer that both SWCNT and MWCNT were effective to remove dyes from an effluent containing high
1) First stage: Protonation of CNTs

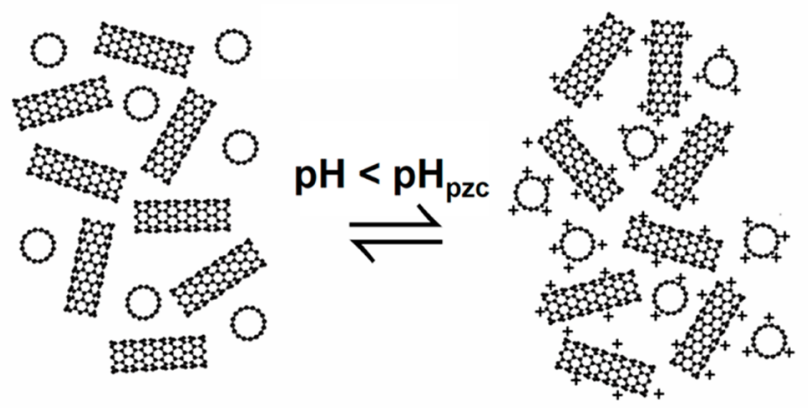

2) Second stage: Dissociation of ARS dye molecules

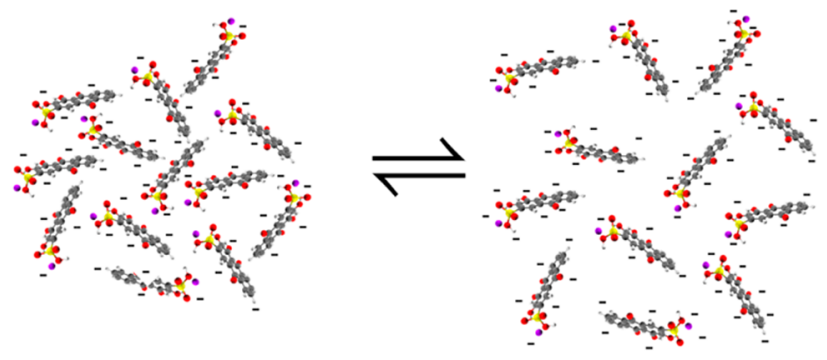

3) Third stage: Electrostatic attraction between CNTs and ARS molecules

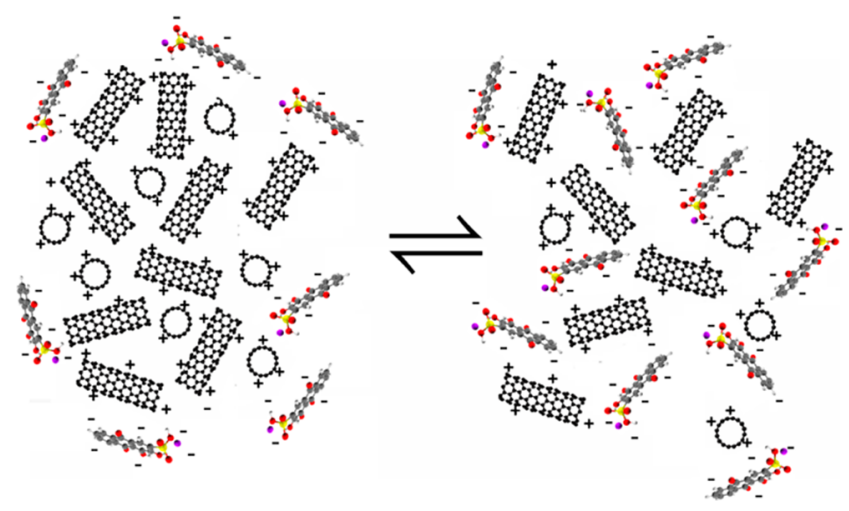

Figure 4. Mechanism of adsorption of ARS dye molecules on CNTs.

salinity and surfactants (see Table 1). Figure S3 shows a photograph of the synthetic effluents $\mathrm{A}$ and $\mathrm{B}$ before and after adsorption by CNT. 

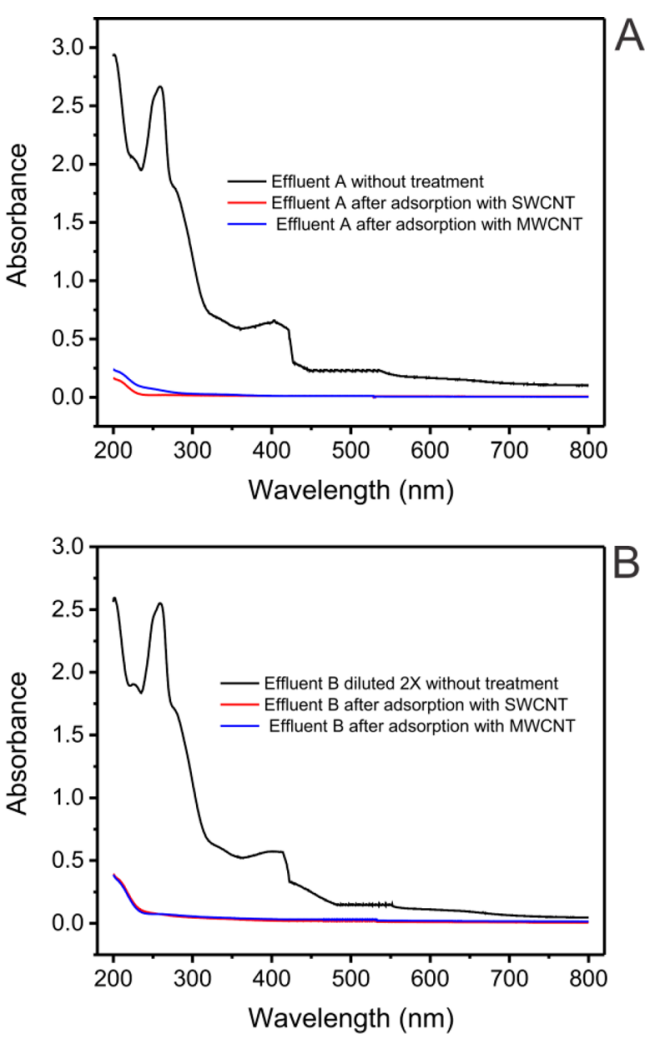

Figure 5. Simulated effluents: (A) effluent A and (B) effluent B.

3.6. Theoretical Results. Figure 6 shows the optimized structure of ARS molecule, its electronic configuration, and

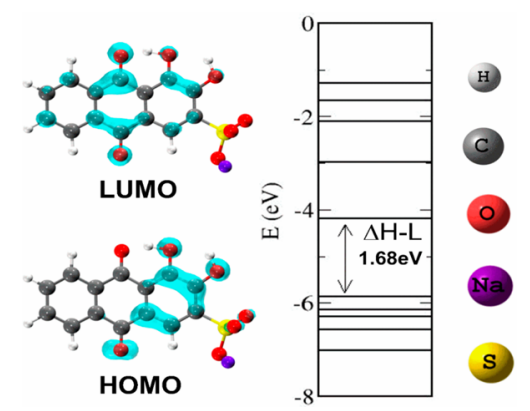

Figure 6. Charge density, electronic levels, and optimized structure for Alizarin Red S dye.

charge densities. It shows that ARS dye has a geometric planar configuration as quoted in the literature. ${ }^{45}$ Electronic charge density analysis was significant to specify the important spots of ARS dye interface with the SWCNT. This analysis also helps to elucidate the ARS dye-SWCNT interaction. Thus, from Figure 5 it may be noted that the ARS dye presents an electronic charge density predominant on the anthraquinone group, instead of the $\mathrm{SO}_{3}+\mathrm{Na}$ group. Certain sites of ARS dye possess a high charge concentration. This directs a possibility that these spots may be subjected to a nucleophilic or an electrophilic attack. ${ }^{46}$

It may be understood from the references ${ }^{21,22}$ that $(5,5)$ SWCNT demonstrated a metallic behavior, while $(8,0)$ SWCNT demonstrated a semiconductor character, displaying $0.6 \mathrm{eV}$ variance between the valence and the conduction bands. $^{21,22}$ The reactivity of the CNT is also significantly influenced by the vacancy. The pristine $(5,5)$ and $(8,0)$ SWCNTs in the vacancy display high charge density, making the site more reactive. ${ }^{47}$ The reason for such phenomenon is because the symmetry is broken in CNT. ${ }^{22}$ Similarly, semiconductor characteristics are shown by both $(16,0)$ and $(25,0)$ SWCNTs with band gaps of 0.45 and $0.26 \mathrm{eV}$, respectively. The band gap reduces as the size of the nanotube increases. Such results correspond to the results reported in the literature. 22,48

The equilibrium geometries of the interaction between ARS dye with both $(5,5)$ and $(8,0)$ SWCNTs with and without vacancy were calculated for several configurations. Figure 7A$\mathrm{D}$ presents the best established configurations achieved from these interactions. Table 6 summarizes the calculated $E_{\mathrm{b}}$. CT and $d_{\mathrm{b}}$ for all of the structures are presented in Figure 6. Low values of binding energies (Table 6) from $(5,5)$ and $(8,0)$ SWCNTs, configurations (A) $-(\mathrm{D})$, specify feeble interface between the adsorbent and the adsorbate. In addition, wider bond distances eliminate the prospects of chemical bonds.

Machado and co-workers established an affiliation between the binding energy from $\mathrm{ab}$ initio calculations and the enthalpy of the experimental system. ${ }^{21}$ Enthalpy values between 20 and $80 \mathrm{~kJ} \mathrm{~mol}^{-1}$ are characteristic of the electrostatic interaction. ${ }^{21}$ Thus, according to Table 6, configurations (B)-(D) exhibited binding energy of less than $0.82 \mathrm{eV}$ or $80 \mathrm{~kJ} \mathrm{~mol}^{-1}$, that is, binding energies characteristic of electrostatic interactions. Therefore, the theoretical and experimental results were found to be in agreement.

Despite configuration (A) presenting a binding energy $>80$ $\mathrm{kJ} \mathrm{mol}^{-1}$ (Table 6), this was not sufficient to state the interaction as chemisorption. ${ }^{22}$ The bond distance and charge transfer from other configurations studied, (B) - (D), were also in the same order. In addition, no structural deformation could be visualized when comparing before and after the adsorption of ARS dye on pristine $(5,5)$ SWCNT, thus excluding the possibility of formation of chemicals bonds to configuration (A). Last, as shown in Table 6, for all configurations studied, the ARS dye assumes an electron acceptor character, and this charge transfer is more significant to $(5,5)$ SWCNT than for $(8,0)$ SWCNT. Thus, the $(5,5)$ SWCNT exhibits a higher binding energy than $(8,0)$ SWCNT for the ARS dye.

The optimized configuration for ARS interacting with $(5,5)$ and $(8,0)$ SWCNTs is the one that is in line and parallel to the nanotube axis (Figure 7). The reason for the same may be because the charge density was concentrated on the anthraquinone group of the ARS dye. The parallel configuration provides a greater amount of available sites that can interact with the side wall of $(5,5)$ and $(8,0)$ SWCNTs. This trend was maintained for the nanotubes with vacancy. It was interesting to see that for nanotubes with vacancy, the sodium ion does not migrate to the vacancy to stabilize the shaky bonds for all configurations. The dangling bonds, in this system, tend to be stabilized by rearrangement of the carbon atoms from nanotubes. In the case of nanotubes with vacancy, chemical bonds or chemisorption were not observed.

The electron acceptor character of ARS dye can be noted by analyzing the energy bands in Figure $7 \mathrm{C}$ and D. It may be seen that there is a flat level adjacent to the bottom of the conduction band (around $4.2 \mathrm{eV}$ ). This assigns an acceptor character to ARS dye in this configuration. The band structures observed from the configurations of (A) and (B) show there was a little mixing, between the levels of the ARS dye with the $(5,5)$ SWCNT, right above the valence band. In configuration 

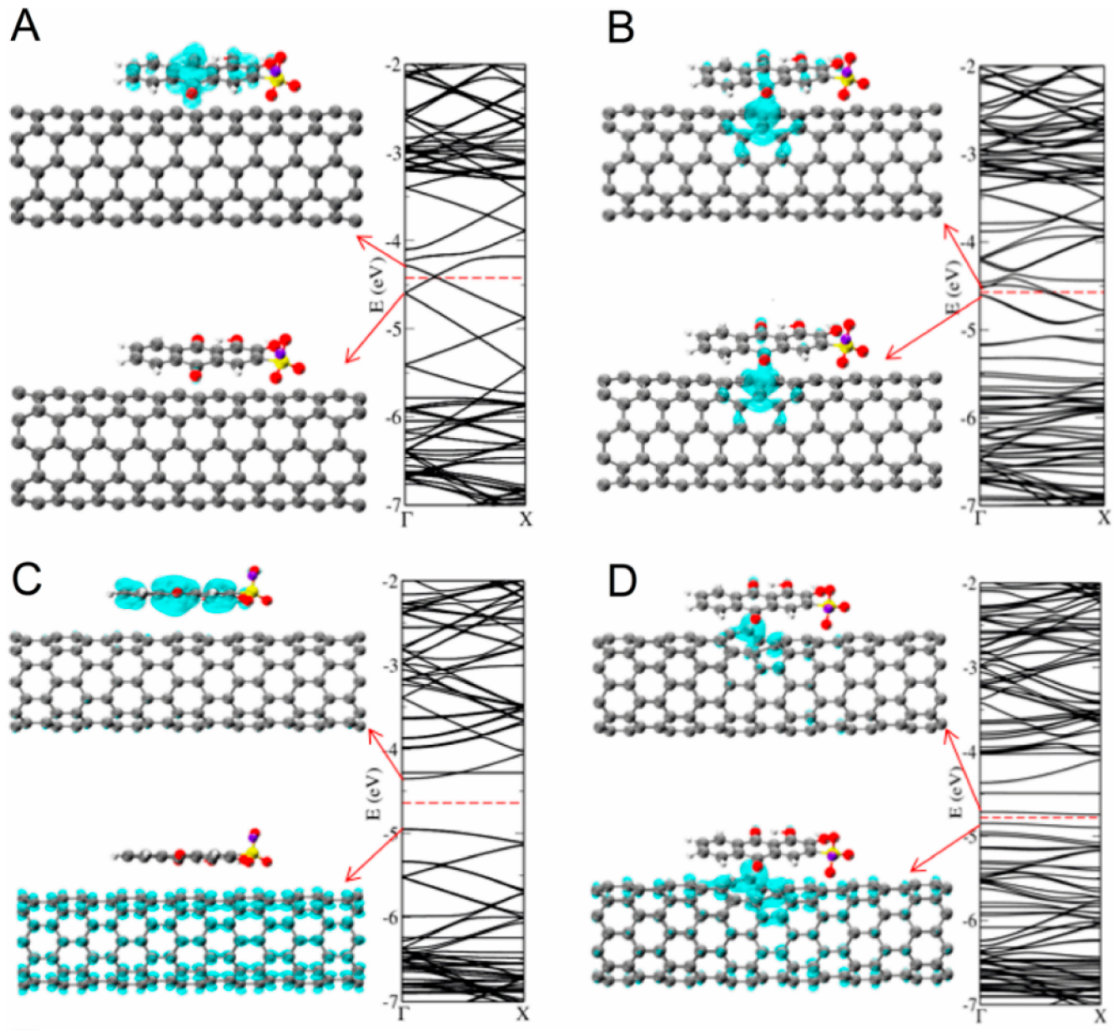

E

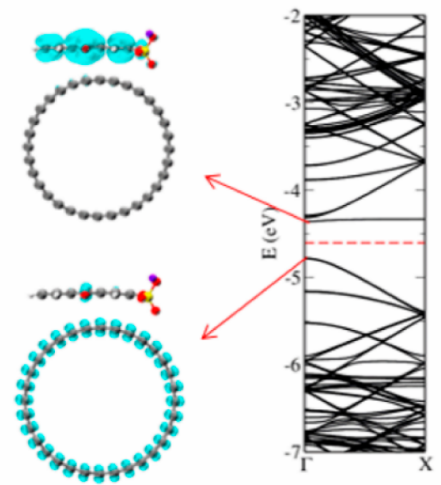

$\mathrm{F}$

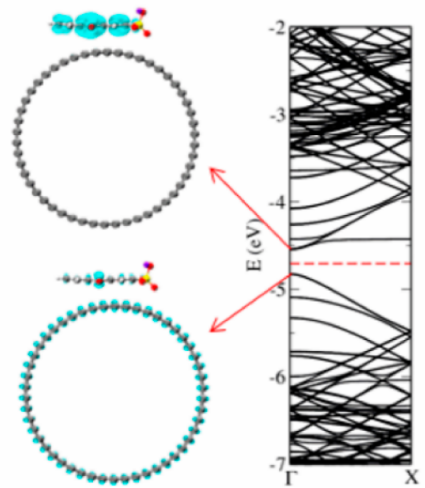

Figure 7. Charge density, energy bands, and optimized configuration for (A) pristine $(5,5)$ SWCNT - ARS; $(B)$ pristine $(5,5)$ SWCNT + vacancy ARS; (C) pristine $(8,0)$ SWCNT - ARS; (D) pristine $(8,0)$ SWCNT + vacancy - ARS; (E) pristine $(16,0)$ SWCNT - ARS; and (F) pristine $(25,0)$ SWCNT - ARS. The isosurface value for the plot was $0.0001 \mathrm{e}^{-} \mathrm{A}^{-3}$ to all configurations.

Table 6. Relevant Data for $E_{\mathrm{b}}, d_{\mathrm{b}}$, and CT to ARS Dye Interacting with $(5,5)$ and $(8,0)$ SWCNTs; $(5,5)$ and $(8,0)$ SWCNTs + Vac; and $(16,0)$ and $(25,0)$ SWCNTs $^{a}$

\begin{tabular}{|c|c|c|c|c|c|}
\hline \multirow[b]{2}{*}{ configurations } & \multirow[b]{2}{*}{ bond-sites } & \multirow[b]{2}{*}{$\begin{array}{c}d_{\mathrm{b}} \\
(\AA)\end{array}$} & \multirow[b]{2}{*}{$\begin{array}{c}C T \\
\text { (electrons) }\end{array}$} & \multicolumn{2}{|c|}{$E_{\mathrm{b}}$} \\
\hline & & & & $\mathrm{eV}$ & $\mathrm{kJ} \mathrm{mol}^{-1}$ \\
\hline A & $\mathrm{C}_{\mathrm{SWCNT}}-\mathrm{O}_{\text {dye }}$ & 2.90 & -0.10 & 1.05 & 101.31 \\
\hline B & $\mathrm{C}_{\mathrm{SWCNT}}-\mathrm{C}_{\text {dye }}$ & 2.83 & -0.10 & 0.65 & 62.71 \\
\hline $\mathrm{C}$ & $\mathrm{C}_{\mathrm{SWCNT}}-\mathrm{O}_{\text {dye }}$ & 2.74 & -0.01 & 0.81 & 78.15 \\
\hline $\mathrm{D}$ & $\mathrm{C}_{\mathrm{SWCNT}}-\mathrm{C}_{\mathrm{dye}}$ & 2.92 & -0.01 & 0.55 & 53.06 \\
\hline $\mathrm{E}$ & $\mathrm{C}_{\mathrm{SWCNT}}-\mathrm{O}_{\mathrm{dye}}$ & 2.80 & -0.05 & 1.52 & 146.66 \\
\hline F & $\mathrm{C}_{\mathrm{SWCNT}}-\mathrm{O}_{\text {dye }}$ & 3.02 & -0.07 & 1.65 & 159.20 \\
\hline
\end{tabular}

${ }^{a}$ Negatives values for CT specify an interaction between the SWCNT and ARS dye. ARS dyes act as a charge acceptor.

(B), there was a break in degeneracy in some levels, at the lower end of the conduction band (caused due a vacancy). Before and after the adsorption of ARS dye, no significant electronic change had occurred. The structural and electronic properties of these nanotubes remain unchanged by the adsorption of the dye, showing a weak interface between them.

Analyses of the charge density of (A), (C), and (D) configurations revealed that there is a large charge density on nanotubes for valence band. In the case of the conduction band, a charge density displacement was observed for the ARS dye (or between the ARS dye and the SWCNT), thus demonstrating a possible charge migration between these systems. It may be noted from Figure $6 \mathrm{~B}$ that the charge density level is the nearest to the Fermi level, which is due to a vacancy in the nanotube. Therefore, the charge density is highly concentrated on vacancy in this configuration.

In Table 6, the (E) and (F) configurations show the values of $E_{\mathrm{b}}, d_{\mathrm{b}}$, and CT of ARS dye interacting with $(16,0)$ and $(25,0)$ SWCNTs. Because of the high computational cost, we chose only one configuration to be analyzed for the effect of diameter on the adsorption study. The configuration chosen is the one 
where the ARS dye is in right angles to the nanotube axis. The lower the values of charge migration and the bigger the values of bond gap indicate that the ARS dye interacts weakly with the SWCNTs, regardless of its diameter. The bond distances were in a similar range when compared to several studies previously reported in the literature. ${ }^{49-51}$ However, it was noteworthy that the value of binding energy increased as the diameter increased, revealing that there is a more effective interaction between ARS dye-SWCNT for larger diameter nanotubes. An increase in binding energy as SWCNT diameter becomes larger could be related to the increase of $\pi-\pi$ interaction between the anthraquinone group of ARS dye and the sidewall of the nanotubes.

In Figure $6 \mathrm{E}$ and $\mathrm{F}$, it can be noted that a straight level close to the bottom of the conduction band (about $4.2 \mathrm{eV}$ ), characteristic of the ARS dye, remains predominantly flat along the first Brillouin zone. Thereby, the levels of the dye present only a slight overlap with the levels of the nanotubes, indicating a feeble interaction between the ARS dye with $(16,0)$ and $(25,0)$ SWCNTs. In addition, no significant change could be observed in structural geometry or in electronic character of both nanotubes. The nanotubes maintain their distances $\mathrm{C}-\mathrm{C}$ of approximately $1.42 \AA$ and remain as semiconductors. These results again reinforce that there is no chemical bond between ARS and SWCNTs. Thus, the increase in binding energy when comparing $(8,0),(16,0)$, and $(25,0)$ SWCNTs seems to be caused exclusively by the increase of $\pi-\pi$ interactions as the diameter becomes larger. At last, analyzing the charge density in Figure $6 \mathrm{E}$ and $\mathrm{F}$, the charge acceptor tendency of ARS dye can be noted. The conduction band shows a high charge density on the ARS dye, while the valence band has a greater concentration of charge on nanotubes with a small charge concentration on the oxygen atoms of the anthraquinone group, that is, is more reactive.

\section{CONCLUSIONS}

Single-walled carbon nanotubes (SWCNT) and multiwalled carbon nanotubes (MWCNT) were successfully employed as nanoadsorbents in the treatment of Alizarin Red $S$ dye. The influences of variables such as $\mathrm{pH}$, temperature, and shaking time on the adsorption efficiency of CNTs were investigated. $\mathrm{pH} 2.0$ was found to be favoring the adsorption process by protonating the CNTs. The contact time was fixed at 65 and $100 \mathrm{~min}$ for SWCNT and MWCNT, respectively. The generalorder kinetic model proved to best fit the experimental data. The equilibrium data were seen to be best fit in the Liu isotherm model. The maximum adsorption capacity of the ARS dye was 312.5 and $135.2 \mathrm{mg} \mathrm{g}^{-1}$ for SWCNT and MWCNT, at $318 \mathrm{~K}$, respectively. The thermodynamic parameters $\Delta G^{\circ}, \Delta S^{\circ}$, and $\Delta H^{\circ}$ were evaluated. The enthalpy values and electrostatic interaction (between ARS and both of the CNTs) were found to be in coordination. The $a b$ initio evaluation of this study projected that the interaction of ARS dye with both $(5,5)$, and $(8,0)$ SWCNTs, with and without vacancy, showed feeble binding energies. This is characteristic of the electrostatic interaction. These results correspond to the experimental predictions. When ARS was planar or parallel to the nanotubes, the most stable configurations were obtained. This observation was predominantly due to $\pi-\pi$ interactions between dyes and nanotubes. The charge acceptor character of ARS causes a substantial decrease in binding energy, comparing the interaction between this dye with no-vacancy configurations $(5,5)$ and $(8,0)$ SWCNTs and with vacancy configurations
$(5,5)$ and $(8,0)$ SWCNTs. As the nanotube diameter increased, the binding energy between the nanotubes and dyes also increased. This study shows that CNT may be utilized as an efficient adsorbent for environmental remediation.

\section{ASSOCIATED CONTENT}

S Supporting Information

The Supporting Information is available free of charge on the ACS Publications website at DOI: 10.1021/acs.jpcc.6b03884.

Additional figures and references (PDF)

\section{AUTHOR INFORMATION}

\section{Corresponding Author}

*Phone: +55 (53) 3921-1251. Fax: +55 (53) 3228-3705. Email: fernando.machado@hotmail.com.br,fernando.machado@ ufpel.edu.br.

Notes

The authors declare no competing financial interest.

\section{ACKNOWLEDGMENTS}

We are thankful to Conselho Nacional de Desenvolvimento Científico e Tecnológico ( $\mathrm{CNPq}$, Brazil), to Coordenação de Aperfeiçoamento de Pessoal de Nivel Superior (CAPES, Brazil), and to Clean Water Mission Project (ESC - 00306, India) for sponsorship and fellowships. We are also thankful to Centro Nacional de Processamento de Alto Desempenho (CENAPAD - SP, Brazil). We are also grateful to Chemaxon for giving an academic research license for the Marvin Sketch software, Version 16.6.6.0 (http://www.chemaxon.com).

\section{REFERENCES}

(1) Moriguchi, T.; Yano, K.; Nakagawa, S.; Kaji, A. Elucidation of adsorption mechanism of bone-staining agent alizarin red $S$ on hydroxyapatite by FT-IR microspectroscopy. J. Colloid Interface Sci. 2003, 260, 19-25.

(2) Jeremić, S.; Filipović, N.; Peulić, A.; Marković, Z. Thermodynamical aspect of radical scavenging activity of alizarin and alizarin red S. Theoretical comparative study. Comput. Theor. Chem. 2014, 1047, $15-21$.

(3) Ghaedi, M.; Hassanzadeh, A.; Kokhdan, S. N. Multiwalled Carbon Nanotubes as Adsorbents for the Kinetic and Equilibrium Study of the Removal of Alizarin Red S and Morin. J. Chem. Eng. Data 2011, 56, 2511-2520.

(4) Roosta, M.; Ghaedi, M.; Mohammadi, M. Removal of Alizarin Red $S$ by gold nanoparticles loaded on activated carbon combined with ultrasound device: Optimization by experimental design methodology. Powder Technol. 2014, 267, 134-144.

(5) Gholivand, M. B.; Yamini, Y.; Dayeni, M.; Seidi, S.; Tahmasebi, E. Adsorptive removal of alizarin red-S and alizarin yellow GG from aqueous solutions using polypyrrole-coated magnetic nanoparticles. J. Environ. Chem. Eng. 2015, 3, 529-540.

(6) Cardoso, N. F.; Lima, E. C.; Royer, B.; Bach, M. V.; Dotto, G. L.; Pinto, L. A. A.; Calvete, T. Comparison of Spirulina platensis microalgae and commercial activated carbon as adsorbents for the removal of Reactive Red 120 dye from aqueous effluents. J. Hazard. Mater. 2012, 241-242, 146-153.

(7) De Lima, R. O. A.; Bazo, A. P.; Salvadori, D. M. F.; Rech, C. M.; Oliveira, D. P.; Umbuzeiro, G. A. Mutagenic and carcinogenic potential of a textile azo dye processing plant effluent that impacts a drinking water source. Mutat. Res., Genet. Toxicol. Environ. Mutagen. 2007, 626, 53-60.

(8) Caritá, R.; Marin-Morales, M. A. Induction of chromosome aberrations in the Allium cepa test system caused by the exposure of seeds to industrial effluents contaminated with azo dyes. Chemosphere 2008, 5, 722-725. 
(9) Alencar, W. S.; Lima, E. C.; Royer, B.; dos Santos, B. D.; Calvete, T.; da Silva, E. A.; Alves, C. N. Application of aqai stalks as biosorbents for the removal of the dye Procion Blue MX-R from aqueous solution. Sep. Sci. Technol. 2012, 47, 513-526.

(10) Jauris, I. M.; Matos, C. F.; Saucier, C.; Lima, E. C.; Zarbin, A. J. G.; Fagan, S. B.; Machado, F. M.; Zanella, I. Adsorption of sodium diclofenac on graphene: a combined experimental and theoretical study. Phys. Chem. Chem. Phys. 2016, 18, 1526-1536.

(11) Dos Santos, D. C.; Adebayo, M. A.; Lima, E. C.; Pereira, S. F. P.; Cataluña, R.; Saucier, C.; Thue, P. S.; Machado, F. M. Application of Carbon Composite Adsorbents Prepared from Coffee Waste and Clay for the Removal of Reactive Dyes from Aqueous Solutions. J. Braz. Chem. Soc. 2015, 26, 924-938.

(12) Saucier, C.; Adebayo, M. A.; Lima, E. C.; Cataluña, R.; Thue, P. S.; Prola, L. D. T.; Puchana-Rosero, M. J.; Machado, F. M.; Pavan, F.; Dotto, G. L. Microwave-assisted activated carbon from cocoa shell as adsorbent for removal of sodium diclofenac and nimesulide from aqueous effluents. J. Hazard. Mater. 2015, 289, 18-27.

(13) Dotto, G. L.; Lima, E. C.; Pinto, L. A. A. Biosorption of food dyes onto Spirulinaplatensis nanoparticles: Equilibrium isotherm and thermodynamic analysis. Bioresour. Technol. 2012, 103, 123-130.

(14) Dos Santos, D. C.; Adebayo, M. A.; Pereira, S. F. P.; Prola, L. D. T.; Cataluña, R.; Lima, E. C.; Saucier, C.; Gally, C. R.; Machado, F. M. New carbon composite adsorbents for the removal of textile dyes from aqueous solutions: kinetic, equilibrium, and thermodynamic studies. Korean J. Chem. Eng. 2014, 31, 1470-1479.

(15) Puchana-Rosero, M. J.; Adebayo, M. A.; Lima, E. C.; Machado, F. M.; Thue, P. S.; Vaghetti, J. C. P.; Umpierres, C. S.; Gutterres, M. Microwave-assisted activated carbon obtained from the sludge of tannery-treatment effluent plant for removal of leather dyes. Colloids Surf., A 2016, 504, 105-115.

(16) Machado, F. M.; Bergmann, C. P.; Fernandes, T. H. M.; Lima, E. C.; Royer, B.; Calvete, T.; Fagan, S. B. Adsorption of Reactive Red $\mathrm{M}-2 \mathrm{BE}$ dye from water solutions by multi-walled carbon nanotubes and activated carbon. J. Hazard. Mater. 2011, 192, 1122-1131.

(17) Gautam, R. K.; Mudhoo, A.; Chattopadhyaya, M. C. Kinetic, equilibrium, thermodynamic studies and spectroscopic analysis of Alizarin Red S removal by mustard husk. J. Environ. Chem. Eng. 2013, 1, 1283-1291.

(18) Fayaz, M.; Ghanei-Motlagh, M.; Taher, M. A. The adsorption of basic dye (Alizarin red $\mathrm{S}$ ) from aqueous solution onto activated carbon $/ \gamma-\mathrm{Fe}_{2} \mathrm{O}_{3}$ nano-composite: Kinetic and equilibrium studies. Mater. Sci. Semicond. Process. 2015, 40, 35-43.

(19) Prola, L. D. T.; Machado, F. M.; Bergmann, C. P.; de Souza, F. E.; Gally, C. R.; Lima, E. C.; Adebayo, M. A.; Dias, S. L. P; Calvete, T. Adsorption of Direct Blue 53 dye from aqueous solutions by multiwalled carbon nanotubes and activated carbon. J. Environ. Manage. 2013, 130, 166-175.

(20) Bergmann, C. P.; Machado, F. M. Carbon Nanomaterials as Adsorbents for Environmental and Biological Applications; Springer International Publishing: New York City, 2015.

(21) Machado, F. M.; Bergmann, C. P.; Lima, E. C.; Royer, B.; dos Santos, B. D.; Fagan, S. B.; Jauris, I. M.; Calvete, T. Adsorption of Reactive Blue 4 dye from water solutions by carbon: experiment and theory. Phys. Chem. Chem. Phys. 2012, 14, 11139-11153.

(22) Jauris, I. M.; Fagan, S. B.; Adebayo, M. A.; Machado, F. M. Adsorption of acridine orange and methylene blue synthetic dyes and anthracene on single wall carbon nanotubes: A first principle approach. Comput. Theor. Chem. 2016, 1076, 42-50.

(23) Kohn, W.; Sham, L. J. Self-consistent equations including exchange and correlation effects. Phys. Rev. 1965, 140, A1133-A1138.

(24) Soler, J. S.; Artacho, E.; Gale, J. D.; García, A.; Junquera, J.; Ordejón, P.; Sánchez-Portal, D. The SIESTA method for ab Initio order-N materials simulation. J. Phys.: Condens. Matter 2002, 14, $2745-2779$.

(25) Sankey, O. F.; Niklewski, D. J. Ab initio multicenter tightbinding model for molecular-dynamics simulations and other applications in covalent systems. Phys. Rev. B: Condens. Matter Mater. Phys. 1989, 40, 3979-3995.
(26) Ceperley, D. M.; Alder, B. J. Ground state of the electron gas by a stochastic method. Phys. Rev. Lett. 1980, 45, 566-569.

(27) Perdew, J. P.; Zunger, A. Self-interaction correction to densityFunctional approximations for many-electron systems. Phys. Rev. B: Condens. Matter Mater. Phys. 1981, 23, 5048-5079.

(28) Troullier, N.; Martins, J. L. Efficient pseudopotentials for planewave calculations. Phys. Rev. B: Condens. Matter Mater. Phys. 1991, 43, 1993-2006.

(29) Monkhorst, H. J.; Pack, J. D. Special points for Brillouin-Zone integrations. Phys. Rev. B 1976, 13, 5188-5192.

(30) Boys, S. F.; Bernardi, F. The calculation of small molecular interactions by the differences of separate total energies. Some procedures with reduced errors. Mol. Phys. 1970, 19, 553-566.

(31) Saucier, C.; Adebayo, M. A.; Lima, E. C.; Prola, L. D. T.; Thue, P. S.; Umpierres, C. S.; Puchana-Rosero, M. J.; Machado, F. M. Comparison of a homemade Bacury shell activated carbon with MWCNT for the removal of Brilliant Blue FCF food dye from aqueous solutions. Clean: Soil, Air, Water 2015, 43, 1389-1400.

(32) Calvete, T.; Lima, E. C.; Cardoso, N. F.; Dias, S. L. P.; Ribeiro, E. S. Removal of brilliant green dye from aqueous solutions using home made activated carbons. Clean: Soil, Air, Water 2010, 38, 521532.

(33) Saucier, C.; Adebayo, M. A.; Lima, E. C.; Prola, L. D. T.; Thue, P. S.; Umpierres, C. S.; Puchana-Rosero, M. J.; Machado, F. M. Comparison of a homemade Bacury shell activated carbon with MWCNT for the removal of Brilliant Blue FCF food dye from aqueous solutions. Clean: Soil, Air, Water 2015, 43, 1389-1400.

(34) Ren, X.; Chen, C.; Nagatsu, M.; Wang, X. Carbon nanotubes as adsorbents in environmental pollution management: a review. Chem. Eng. J. 2011, 170, 395-410.

(35) Yang, Q. H.; Hou, P. X.; Bai, S.; Wang, M. Z.; Cheng, H. M. Adsorption and capillarity of nitrogen in aggregated multi-walled carbon nanotubes. Chem. Phys. Lett. 2001, 345, 18-24.

(36) Ghaedi, M.; Najibi, A.; Hossainian, H.; Shokrollahi, A.; Soylak, M. Kinetic and equilibrium study of alizarin red $S$ removal by activated carbon. Toxicol. Environ. Chem. 2012, 94, 40-48.

(37) Rehman, R.; Mahmud, T. Sorptive elimination of alizarin red-S dye from water using Citrullus lanatus peels in environmentally benign way along with equilibrium data modeling. Asian J. Chem. 2013, 25, $5351-5356$.

(38) Fan, L.; Zhang, Y.; Li, X.; Luo, C.; Lu, F.; Qiu, H. Removal of alizarin red from water environment using magnetic chitosan with alizarin red as imprinted molecules. Colloids Surf., B 2012, 91, 250257.

(39) Fu, F.; Gao, Z.; Gao, L.; Li, D. Effective Adsorption of Anionic Dye, Alizarin Red S, from Aqueous Solutions on Activated Clay Modified by Iron Oxide. Ind. Eng. Chem. Res. 2011, 50, 9712-9717.

(40) Albadarin, A. B.; Mangwand, C. Mechanisms of Alizarin Red S and Methylene blue biosorption onto olive stone by-product: Isotherm study in single and binary systems. J. Environ. Manage. 2015, 164, 8693.

(41) Kuo, C. Y.; Wu, C. H.; Wu, J. Y. Adsorption of direct dyes from aqueous solutions by carbon nanotubes: determination of equilibrium, kinetics and thermodynamics parameters. J. Colloid Interface Sci. 2008, $327,308-315$.

(42) Travlou, N. A.; Kyzas, G. Z.; Lazaridis, N. K.; Deliyanni, E. A. Graphite oxide/chitosan composite for reactive dye removal. Chem. Eng. J. 2013, 217, 256-265.

(43) Kyzas, G. Z.; Lazaridis, N. K.; Bikiaris, D. N. Optimization of chitosan and $\beta$-cyclodextrin molecularly imprinted polymer synthesis for dye adsorption. Carbohydr. Polym. 2013, 91, 198-208.

(44) Cardoso, N. F.; Lima, E. C.; Pinto, I. S.; Amavisca, C. V.; Royer, B.; Pinto, R. B.; Alencar, W. S.; Pereira, S. F. P. Application of cupuassu shell as biosorbent for the removal of textile dyes from aqueous solution. J. Environ. Manage. 2011, 92, 1237-1247.

(45) Liu, C. H.; Li, J. J.; Zhang, H. L.; Li, B. R.; Guo, Y. Structure dependent interaction between organic dyes and carbon nanotubes. Colloids Surf., A 2008, 313, 9-12. 
(46) Bader, R. F. W.; MacDougall, P. J. Toward a theory of chemical reactivity based on the charge density. J. Am. Chem. Soc. 1985, 107, 6788-6795.

(47) Peres, N. M. R.; Guinea, F.; Castro Neto, A. H. Electronic properties of disordered two-dimensional carbon. Phys. Rev. B 2006, 73, 125411.

(48) Dresselhaus, M. S.; Dresselhaus, G.; Charlier, J. C.; Hernández, E. Electronic, thermal and mechanical properties of carbon nanotubes. Philos. Trans. R. Soc., A 2004, 362, 2065-2098.

(49) Henwood, D.; Carey, J. D. Ab initio investigation of molecular hydrogen physisorption on graphene and carbon nanotubes. Phys. Rev. B 2007, 75, 245413.

(50) Ganji, M. D. Density functional theory based treatment of amino acids adsorption on single-walled carbon nanotubes. Diamond Relat. Mater. 2009, 18, 662-668.

(51) Lee, H.-J.; Kim, G.; Kwon, Y.-K. Molecular adsorption study of nicotine and caffeine on single-walled carbon nanotubes from first principles. Chem. Phys. Lett. 2013, 580, 57-61. 


\section{Supporting Information}

\section{ADSORPTION OF ALIZARIN RED S DYE BY CARBON NANOTUBES: AN EXPERIMENTAL AND THEORETICAL INVESTIGATION}

Fernando M. Machado ${ }^{1 *}$, Carmalin Sophia A. ${ }^{2}$, Eder C. Lima ${ }^{3}$, Silvio L. P. Dias ${ }^{3}$, Lizie

D. T. Prola ${ }^{3}$, Caroline Saucier ${ }^{3}$, Iuri M. Jauris ${ }^{4}$, Ivana Zanella ${ }^{4}$, Solange B. Fagan ${ }^{4}$

1- Technology Development Center, Federal University of Pelotas (UFPEL), R. Gomes Carneiro 1, ZIP 96010-610, Pelotas, RS, Brazil.

2- National Environmental Engineering Research Institute (NEERI), Chennai Zonal Laboratory, CSIR Campus, Taramani, Chennai 600113, India

3- Institute of Chemistry, Federal University of Rio Grande do Sul (UFRGS), Av. Bento Gonçalves 9500, Postal Box 15003, ZIP 91501-970, Porto Alegre, RS, Brazil.

4- Área de Ciências Tecnológicas, Centro Universitário Franciscano (UNIFRA), R. dos Andradas 1614, ZIP 97010-032, Santa Maria, RS, Brazil.

* Corresponding author: Phone: +55 (53) 3921-1251; FAX: +55 (53) 3228-3705; email: fernando.machado@hotmail.com.br and fernando.machado@ufpel.edu.br 
The Figure S1 shows the structural formula of textile dye Alizarin Red $\mathrm{S}$ (ARS) (Sodium alizarin sulphonate, C.I. 58005; CAS 130-22-3; $\mathrm{C}_{14} \mathrm{H}_{7} \mathrm{NaO}_{7} \mathrm{~S}$; $342.25 \mathrm{~g} \mathrm{~mol}^{-1}$ ) and their pKa values.

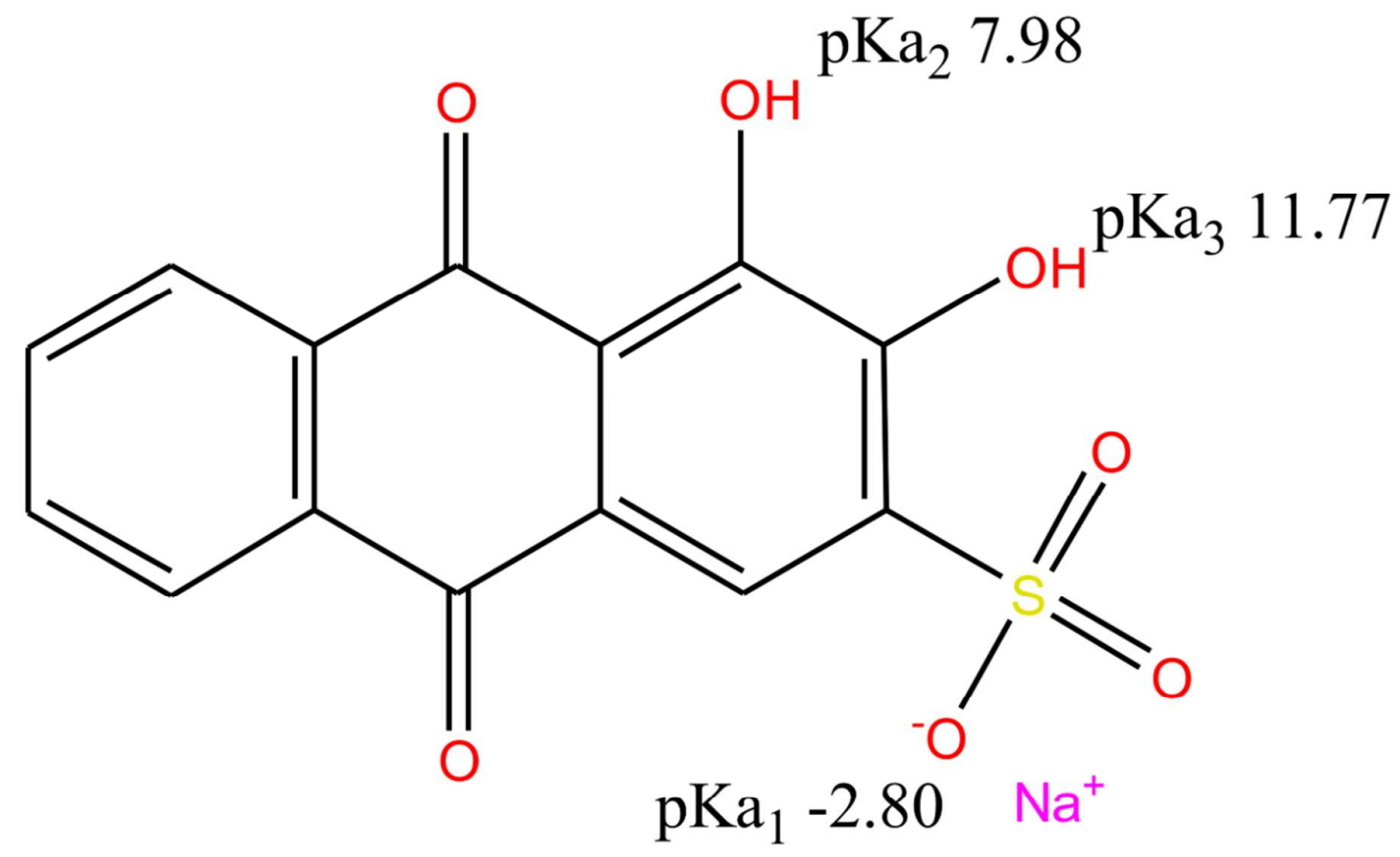

Figure S1. Alizarin Red S structural formula.

The Figure S2 (A) and (B) present the FTIR (Fourier Transform Infrared Spectroscopy) vibrational spectra of the SWCNT and MWCNT respectively. The sharp peaks at $3857 \mathrm{~cm}^{-1}$ and $3736 \mathrm{~cm}^{-1}$ in SWCNT and 3855 and $3737 \mathrm{~cm}^{-1}$ in MWCNT may be attributed to residual metallic catalyst left in the synthesis of CNT. It might have distorted the bands of $\mathrm{O}-\mathrm{H}$ groups present on the CNTs. The intense 
absorption bands at $3443 \mathrm{~cm}^{-1}$ may be assigned to $\mathrm{O}-\mathrm{H}$ bond stretching $[2,3]$. The peaks at 2921 and $2853 \mathrm{~cm}^{-1}$ in the both CNTs may be attributed to aliphatic $\mathrm{C}-\mathrm{H}$ stretches [1]. The sharp peaks observed at $1634 \mathrm{~cm}^{-1}$ for both adsorbents were assigned to the asymmetric carboxylate stretch [2,3]. The bands at 1446 and 1435 $\mathrm{cm}^{-1}$ presented in MWCNT and SWCNT may be assigned to the aromatic rings [2]. The bands observed at $1385 \mathrm{~cm}^{-1}$ in both nanotubes are attributed to $\mathrm{C}-\mathrm{CH}_{2}$ symmetric bend [1]. The strong bands that appeared at $1032 \mathrm{~cm}^{-1}$ in SWCNT, and 1105 and 1102 and $\mathrm{cm}^{-1}$ in MWCNT and SWCNT, respectively, confirmed the presence of a C-O bond [3]. The small peaks at 878 and $875 \mathrm{~cm}^{-1}$ in SWCNT and MWCNT $\mathrm{cm}^{-1}$ respectively are credited to $\mathrm{CH}$ out of plane bends from the aromatic rings [1]. By the functional groups present in both the CNTs, their interactions with the ARS dye should occur through $\mathrm{O}-\mathrm{H}$, aromatic rings and carboxylate, as observed in the previous studies for the interaction of dyes with carbon nanoadsorbents $[2,3]$. 

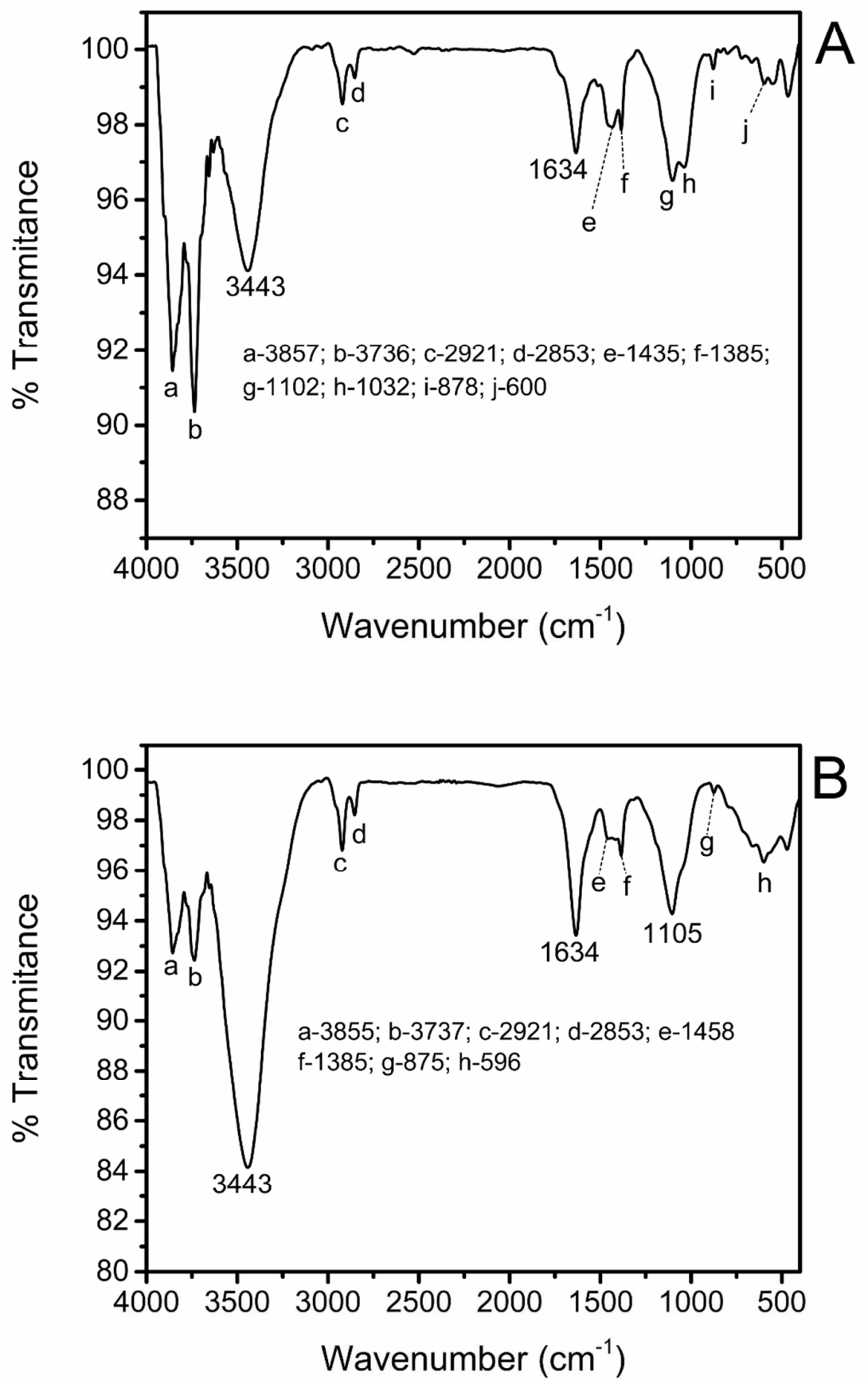

Figure S2. Infrared spectra of nanoadsorbents: (A) SWCNT and (B) MWCNT.

The Figure S3 shows a photograph of the synthetic effluents A and B (see 
the chemical composition of the synthetic effluents in Table 1) before and after the adsorption process by SWCNT and MWCNT.

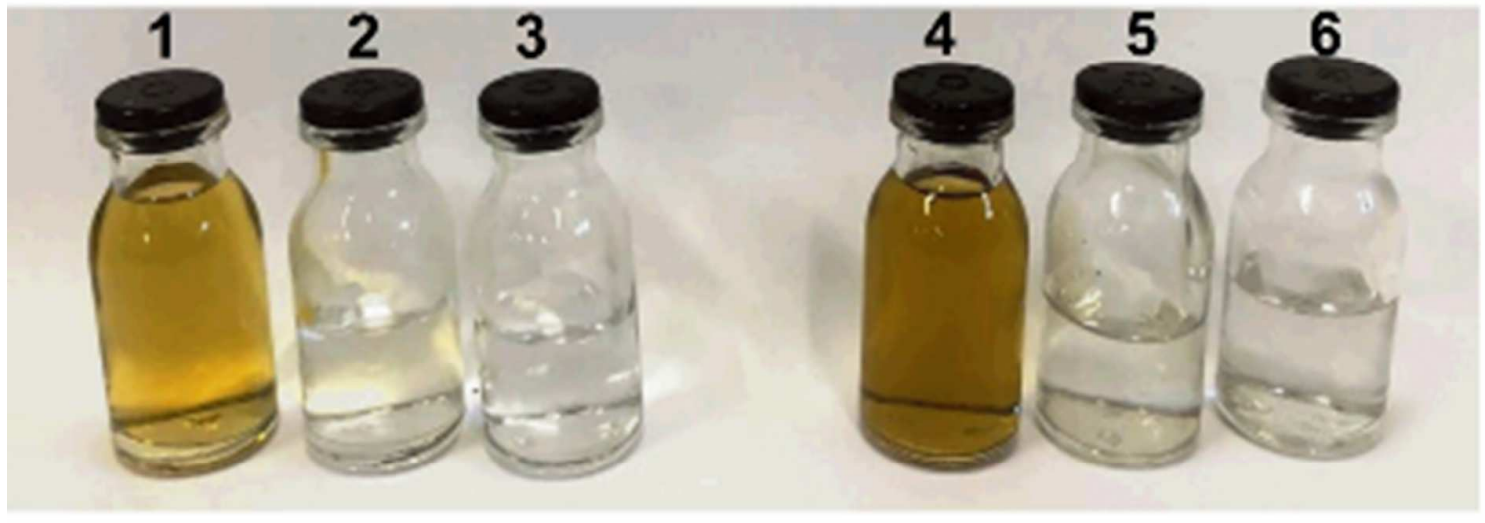

1- Synthetic effluent $A$ before adsorption

2- Synthetic effluent A after adsorption with SWCNT

3- Synthetic effluent A after adsorption with MWCNT

4- Synthetic effluent B before adsorption

5- Synthetic effluent B after adsorption with SWCNT

6- Synthetic effluent B after adsorption with MWCNT

Figure S3. Photograph of the synthetic effluents A and B before and after the adsorption process by the CNTs.

\section{References}

[1] Smith, B. C. Infrared spectral interpretation: a systematic approach. CRC Press: Boca Raton, USA, 1999.

[2] Machado, F. M.; Bergmann, C. P.; Fernandes, T. H. M.; Lima, E. C.; Royer, B.; Calvete, T.; Fagan, S. B. Adsorption of Reactive Red M-2BE dye from water 
solutions by multi-walled carbon nanotubes and activated carbon. J. Hazard. Mater. 2011, 192, 1122-1131.

[3] Machado, F. M.; Bergmann, C. P.; Lima, E. C.; Royer, B.; dos Santos, B. D.; Fagan, S. B.; Jauris I. M.; Calvete, T. Adsorption of Reactive Blue 4 dye from water solutions by carbon: experiment and theory. Phys. Chem. Chem. Phys. 2012, 14, 11139-11153. 